\title{
'O Que Adianta Conhecer Muita Gente e no Fim das Contas Estar Sempre só?' Desafios da maternidade em tempos de Síndrome Congênita do Zika Vírus
}

\author{
Raquel Lustosa C. Alves ${ }^{a}$ \\ Soraya Fleischer ${ }^{\mathrm{b}}$
}

Três anos após o surto do Zika Vírus no Brasil diferentes impactos na população brasileira podem ser evidenciados. A existência de redes de apóio às famílias, composta majoritariamente por mulheres que enfrentam uma situação de vulnerabilidade social anterior à epidemia, contribui tanto para a esfera econômica quanto afetiva das 'mães de micro' - como decidiram se intitulam essas mulheres. Mas, ainda assim, a carga de tarefas direcionadas a essa mulher, seja ela mãe, irmã, avó ou tia, é instransponível. A partir da etnografia realizada com as 'mães de micro' de Recife/PE, o presente trabalho busca refletir as relações de ambiguidade produzidas neste cenário; por um lado, existe um sujeito em processo de empoderamento com as relações construídas através das redes de apoio, por outro lado, tem-se cansaço e solidão. Neste sentido, o olhar antropológico nos ajuda a compreender como essas mulheres têm ressignificado a maternidade e, sobretudo, como a solidão tem sido tema de reflexão, tencionando a intersecsionalidade de gênero, classe, raça e deficiência.

Maternidade, Zika Vírus, Solidão, Antropologia da Saúde.

Pertencente à tríade de arboviroses, com a Dengue e a Chicungunha, o vírus Zika ficou conhecido no verão de 2015, nacionalmente e internacionalmente, por sua correlação com o nascimento de crian-

a Mestranda em Antropologia Social, Universidade Federal de Pernambuco. E-mail: lusraquel@gmail.com.

b Professora Associada ao Departamento de Antropologia, Universidade de Brasília. E-mail: fleischer.soraya@gmail.com. 
ças com malformações fetais como, a exemplo da que se tornou a sua mais intensa metonímia, a microcefalia. Três anos após o surto da epidemia no Brasil, diferentes impactos na população podem ser evidenciados, em especial na vida das mulheres que tiveram filhas e filhos nestas circunstâncias. Embora o alerta sinalizador à saúde pública tenha durado apenas oito meses por parte da Organização Mundial de Saúde $(\mathrm{OMS})^{1}$, a epidemia do Zika Vírus se mostra ainda hoje uma situação emergencial por suas intensas consequências na vida das famílias atingidas.

Diante das várias complicações físicas e neurológicas que os bebês nascidos, com o que a biomedicina veio nomear de Síndrome Congênita do Zika Vírus (SCZV), a microcefalia foi uma das características de maior destaque, transformando-se em uma importante categoria identitária local. $\mathrm{O}$ prefixo foi acionado por essas mulheres de várias formas: elas se identificam como 'mães de micro', seus filhos ficaram conhecidos como 'bebês de micro', e há ainda as 'famílias de micro', 'ONGs de micro', 'clínicas de micro' e assim por diante (Fleischer 2017 e 2018; Alves 2018; Valim 2017; Venâncio 2017). No entanto, outros efeitos da síndrome também devem ser considerados, como nos aponta Venâncio:

"[...] complicações visuais e auditivas, comprometimento motor e cognitivo, doenças articulares e ortopédicas, dificuldade de alimentação e respiração, paralisias cerebrais, deficiências físicas e mentais, e desenvolvimento de outras síndromes como epilepsias refratárias são exemplos de sintomas que se destacam" (Venâncio 2017:11).

Pernambuco, onde a nossa pesquisa de campo tem sido realizada, foi o estado com mais casos de nascimentos de bebês com a SCZV. São quase 4.000 casos em todo país, com cerca de 400 em Pernambu$\mathrm{CO}^{2}$ e metade desse montante concentrada na Região Metropolitana do Recife (RMR). Enquanto epicentro do fenômeno, o estado tem tido maior visibilidade e mobilização política se comparado a outros estados do Nordeste (Alves; Safatle 2018, no prelo; Scott et al. 2017; Longhi \& Pinheiro 2017). Quando comparado a outras regiões, como 
o Norte e Centro-Oeste do país, essa proporção é ainda maior ${ }^{3}$. Mas, se olharmos para dentro do próprio estado, veremos que Recife é a cidade que mais tem recebido atenção e investimento, ainda que de forma limitada. Em decorrência disso, outros munícipios da zona da mata, do sertão e do agreste pernambucanos padecem de um severo vazio de políticas públicas de saúde e educação, a ponto de essas mães precisarem se deslocar por centenas de quilômetros até a capital em busca de serviços de reabilitação, acompanhamento, assistência social para essas crianças. Algumas delas precisaram, inclusive, se mudar para a capital ou inventar arranjos de moradia ou pouso com amigas e parentes na capital.

Diante de tal conjuntura epidemiológica, muitos estudos desde a correlação entre o vírus e a epidemia têm sido realizados a fim de compreender causa e efeito da ocorrência do SCZV, bem como sua gravidade. No entanto, embora tenham sido convocadas a participar intensivamente das pesquisas científicas realizadas na RMR, há um fluxo de comunicação muito limitado entre estes estudos e as 'mães de micro'. Um número relevante de famílias não tomou conhecimento da relação de causa e efeito entre zika e microcefalia, acontecimento que se tornou uma das pautas na agenda das entidades locais, como a exemplo a União de Mães de Anjo (UMA), e que se repercute na agenda das mães ${ }^{4}$. Inclusive, entre as próprias autoridades sanitárias, não havia muitos estudos sobre isso, em razão de ser um fenômeno pouquíssimo estudado na história da epidemiologia. Pouco também se sabe sobre o futuro dessas crianças, com diagnósticos e prognósticos desesperançosos vindos de muitos médicos 5 . O que também tem sido construído é uma "ciência doméstica" (Diniz 2016) realizada tanto pelas famílias, mas também pelas terapeutas e médicas que têm acompanhado diretamente os casos e se permitido aprender com as mães de micro.

Este artigo privilegia, especificadamente, as mães que, por hierarquias de gênero histórica e culturalmente estabelecidas, têm se destacado como as principais - quando não as únicas - cuidadoras dessas crianças. Família, na especificidade deste contexto etnográfico, é com- 
preendida como uma 'estrutura familiar matrifocal', ideia cunhada por R. T. Smith, mas utilizado aqui pela antropóloga Claudia Fonseca, na qual "a prioridade é dada ao laço entre mães e crianças, irmão e irmã, ao passo que o laço conjugal é considerado menos intensivo afetivamente" (Smith 1973:141 apud Fonseca 2004:42). Ou seja, as relações que as mães estabelecem na partilha do cuidado com suas crianças são mais intensamente construídas com outras mulheres da família (mãe, avó, irmã, tia, prima, afins) e com os filhos mais velhos, do que necessariamente com o (ex) cônjuge $^{6}$. Essas relações cooperativas de cuidado se dão com as mulheres de laços consanguíneos, afins e também da rede que tem se formado em razão da síndrome propriamente dita, composta por outras mães de micro, lideranças e colegas dos movimentos sociais, burocratas, terapeutas e profissionais de saúde. $\mathrm{O}$ feminino é o centro dessa extensa rede de cuidados (Diniz 2016).

A carga de tarefas direcionadas a essas mulheres, seja ela mãe, avó ou irmã de micro, é monumental. Elas são responsáveis pelos cuidados diários dessa criança: enfrentam os árduos trajetos nos itinerários terapêuticos; precisam aprender todo um novo léxico, tanto biomédico, quanto burocrático; negociam a presença dos genitores, seja na forma de prestação de cuidados, pagamentos de pensões, oferta de planos de saúde etc.; vivenciam a discriminação de uma sociedade pouco preparada a lidar com a deficiência (Diniz 2010). E, não se pode perder de vista, que são mulheres que já enfrentavam uma situação de vulnerabilidade social anterior à epidemia (Alves 2018), por exemplo, ao residirem em lugares com parco saneamento básico e muito dos imperativos do racismo ambiental (Carvalho 2017), leva-se em conta que cerca de $77 \%$ dessas mulheres são jovens, negras (Brito 2016) ${ }^{7}$ e compõem as classes populares da região.

Além disso tudo, há uma sensação de corrida contra o tempo. $\mathrm{O}$ tempo, em suas diferentes dimensões, é um fio condutor significativo na relação com a SCVZ. Primeiro, há de se ter tempo para cuidar dos filhos. Por um lado, essas mulheres abriram mão de trabalho remunerado, por exemplo, para ter mais tempo disponível. Mas, como 
consequência, precisa fazer mais esforços para equilibrar o orçamento doméstico, agora ainda mais impactado pelas altas despesas exigidas pela síndrome. Segundo, há de se ter tempo para se deslocar, nas difíceis condições do transporte público, para os serviços oferecidos e espalhados ao redor de toda a capital. Terceiro, há que se entender o tempo da criança, que não necessariamente segue o mesmo ritmo de aprendizado e desenvoltura de suas contemporâneas ou mesmo do ritmo esperado pelos profissionais de saúde para uma criança com deficiências ou com a SCVZ, especificamente. Esse tempo se relacionou diretamente com a ideia de 'estimulação precoce', tão preconizada pelos profissionais de saúde da região. Tido como o principal paradigma orientador, fez com que tudo se acelerasse para aproveitar a 'plasticidade' do cérebro e sua abertura para o aprendizado durante os primeiros anos de vida ${ }^{8}$. Por fim, há o tempo pessoal, subjetivo, 'para si mesma', bastante dependente de todos esses aspectos anteriores, mas em geral bastante capturado e diminuído pelo tempo da criança, dos serviços e dos cuidados.

Os desafios, em meio aos desdobramentos incertos da SCVZ, são de diversas ordens. Interessa-nos aqui, enquanto tarefa antropológica, pensar como a noção de maternidade(s) (Pinheiro 2019) tem sido produzida, levando em conta essas personagens e suas interações e relações com outras, a gama de tarefas que têm aprendido e assumido e como tempo é por elas manejado. A maternidade, dita no plural, diz respeito a diversidade de maternidades construídas no panorama do fenômeno, da qual as definições de cuidado são atualizadas em torno dessa experiência 'não homogênea', como classifica o autor Diego Pinheiro (2019). Para essa tarefa, é importante que se torne compreensível como todo um contexto, que envolve essas personagens e tantas outras, torna esta(s) maternidade(s) de micro possível e, eventualmente, mais amena, porque, como ouvimos certa vez em um centro de reabilitação, "uma andorinha só não faz verão" que, traduzido por um provérbio africano, quer dizer, "uma chama não perde nada ao acender outra chama” (Gonçalves 2009:01). 


\section{Como e onde foram conhecidos os desafios maternos diante da SCVZ}

A primeira parte do trabalho pretende mostrar como o tempo tem outra dimensão neste tipo de maternidade. Enquanto, na segunda parte, a discussão considera noções de rede e solidão que atravessam, positivamente ou não, as experiências dessas mulheres. É importante entender a proporção que a epidemia tomou em suas vidas e no modo como foram e têm sido afetadas juntamente com seus filhos pela conhecida SCVZ.

Aqui, procuraremos mostrar como as vivências e as narrativas dessas mães de micro nos provocam a pensar a epidemia sobre outros olhares. Bem como discutir os desafios maternos, principalmente, após esses três anos; como tem sido (res)significada a maternidade e como têm sido construídas (outras) formas de percepção sobre si mesmas. Como as mães têm vivido a maternidade durante esse tempo? Como questões de cuidados, reprodução e conjugalidades têm sido direcionadas? Quais redes têm se fortalecidas e quais foram desfeitas?

Provoca-nos pensar como a maternidade tem sido ressignificada para essas mulheres e, como também, a solidão tem se repercutido nessas trajetórias por conta das desigualdades que os marcadores de gênero, classe, raça e deficiência mobilizam neste contexto. Como afirma Claudia Fonseca, pensar a alteridade a partir disso tudo é valioso porque "é através de uma maior atenção para os estilos das formas expressivas, e com a relação entre estilo e valor que poderemos aprofundar nossa compreensão dos diversos universos simbólicos da sociedade em que vivemos" (Fonseca 2004:132). A aposta é de que ser uma mãe de micro possa ser uma forma expressiva muito eloquente e contemporânea nos/dos dias de hoje, por vezes desafiando, por vezes sucumbindo a um momento específico da história brasileira e latino-americana em que uma guinada governamental neoliberal, que reflete num ideal de estado mínimo e numa progressiva desvalorização dos direitos sociais, tem se fortalecido (Han 2015). 
Os dados que alimentam esse artigo têm sido construídos a partir do diálogo e convivência com um conjunto de cerca de quinze mães de micro que vivem na RMR. Esses dados surgiram no âmbito de uma pesquisa coletiva que conta com várias pesquisadoras de Brasília, Recife e Natal. As mulheres pernambucanas foram contatadas diretamente e sem mediação pela universidade, pelos serviços de saúde ou pelos movimentos sociais. Aceitaram conversar e encontrar conosco. E, desde 2016, elas têm sido revisitadas a cada semestre pelas equipes que não moram em Recife (como é o caso da segunda autora); e reencontradas mais frequentemente pelas equipes que vivem na cidade (como é o caso da primeira autora). Em geral, optamos por conversas informais e menos estruturadas, respeitando as pautas e discussões que essas mulheres propõem. Também, eventualmente, realizamos entrevistas gravadas, assistimos palestras e observamos eventos para os quais elas nos convidam. Contato por mídias sociais (Facebook, WhatsApp e Instagram) é perpetuado quando a presença física se torna menos frequente.

Diários de campo são escritos, editados e compartilhados entre as pesquisadoras. Reuniões, discussões dos dados e, principalmente, a coautorias têm sido incentivadas nessa filosofia de pesquisa coletiva (Carneiro \& Fleischer, no prelo). Nossos esforços estiveram concentrados em estar com essas mulheres e com suas crianças em seus itinerários terapêuticos, desde às suas casas à circulação pelos bairros, em diferentes meios de transporte, pelos centros terapêuticos, hospitais, palestras, seminários acadêmicos e científicos e reuniões dos grupos e ONGs. Foi a partir da etnografia realizada com essas mulheres em tantos espaços e ocasiões que pouco a pouco fomos entendendo o significado da epidemia em suas vidas e na de seus filhos e familiares. "Seguir essas mulheres pela cidade era também entender como tinham aceitado a estimulação precoce como valor e enunciavam o tipo de mãe pelo qual desejavam ser reconhecidas, aquela publicamente comprometida com a deficiência do filho" (Carneiro \& Fleischer 2017:25). Ainda, a atuação das redes de apoio tem sido um espaço muito acolhedor para 
essas mulheres, com ênfase em duas ONGs que têm protagonizado esse espaço, a Aliança das mães e famílias raras (AMAR) e a União de mães de anjos (UMA). Enquanto a primeira ONG surge em 2013 e é voltada para atender famílias e crianças com raros diagnósticos e síndromes e desde 2015 passa a receber as famílias vítimas da SCZV, a segunda $\mathrm{ONG}$ surge especificamente das demandas e emergências do epifenômeno, em 2016, reagindo aos interesses e necessidades das 'famílias de micro' (Scott et al. 2017).

Procuramos refletir sobre as relações de ambiguidade produzidas neste cenário; por um lado existe um sujeito se empoderando com as relações construídas através das redes de apoio, por outro lado temse uma mãe viajante e cansada (Alves 2017) que vivencia itinerários solitários e cumpre uma agenda de tarefas dedicadas exclusivamente a um filho com demandas específicas. Uma de nossas anfitriãs resumiu esse dilema: "O que adianta conhecer muita gente e no fim das contas estar sempre só?”. Diante disso, tem-se um cenário de muitos desafios, tanto por parte das instituições públicas, dos profissionais de saúde, das crianças atingidas como, e principalmente, por parte das cuidadoras. Elas oscilam constantemente entre esforços individuais e coletivos para cuidar dessas crianças. Nesse artigo, traremos algumas passagens, cenários e formulações por parte dessas mulheres que temos acompanhado.

\section{'O tempo é o que me mata': desafios com a cidade, os serviços de saúde, o cuidado}

Durante uma sessão de 'estimulação precoce' realizada em um dos centros terapêuticos do Recife, Elisa se questionava sobre a falta de tempo para cuidar de si mesma, falava da vontade de descansar ou de fazer qualquer outra atividade que gostasse. Elisa é uma mulher branca com seus trinta e cinco anos. Naquele dia, ela havia acordado às três da manhã para se preparar e preparar a filha, Dora, para mais uma viagem do município onde mora até Recife. Ao acordar, deu a 
dose de um remédio anticonvulsionante para filha, reuniu as fraldas, os remédios, os documentos e pôs na mochila junto a uma blusinha de frio extra - pois as salas de terapia costumam ser muito refrigeradas. Tomou banho, deu banho em Dora e esperou pacientemente o motorista do carro da prefeitura passar em sua casa para buscá-las e, assim, seguirem para mais uma jornada terapêutica. Ao chegar em uma das instituições, às seis horas da manhã, aguardou a vez da filha ser atendida. À sua frente, já havia pelo menos outras duas mães, também do interior, que aguardavam o atendimento da fonoaudióloga que começaria o trabalho às $8 \mathrm{~h}$.

Dentro dos centros terapêuticos muito é compartilhado. Naquela manhã, Elisa e suas companheiras na sala de espera trocaram informações sobre preço e eficácia de um ou outro remédio; compararam sinais de avanço entre os filhos; repassaram informações sobre terapias que foram bem replicadas em casa; falaram sobre posturas e prognósticos médicos desestimulantes, sobre conjugalidades e afetos, e, também, sobre a maratona cirúrgica que seus filhos no momento vivenciavam. Esse ciclo de conversas era parte, como nos mostraram Carneiro \& Fleischer, de:

"uma forte sociabilidade [que] por ali se realizava, com ares de solidariedade, comadrio feminino, conforto emocional, apoio mútuo e diversos tipos de trocas (fraldas, medicamentos, telefone de médicas especialistas, produtos de beleza, alimentos, presentes, convites para festas de aniversário e batizado)" (Carneiro \& Fleischer 2017:28).

Quando não compartilhavam essa atenção umas com as outras, o tempo era intensificado de outras formas. Aproveitavam o intervalo por vezes espaçado, entre uma sessão ou outra, para descansar ou tirar um cochilo, enquanto, gentilmente, outras mães olhavam seu filho. Ou comprar um lanche ou cozinhar uma refeição (algumas clínicas ofereciam cozinha ou, ao menos, um micro-ondas), acompanhar e/ ou postar notícias pelo telefone celular, organizar fotografias em seus arquivos eletrônicos, resolver pendências burocráticas no balcão de atendimento, continuar um trabalho manual que lhes desse uma ren- 
da complementar, como um tricô, bordado, artesanato, ou mesmo fazer circular o catálogo de venda de cosméticos.

Após as sessões terapêuticas, Dora e Elisa aguardaram ansiosamente o motorista lhes buscar para a segunda parte da viagem naquele dia. Desta vez, não iriam para a AMAR, nem para a UMA, mas para casa. Elisa estava preocupada com o horário e temia que o motorista atrasasse, como havia acontecido das últimas vezes em que ele precisava estar ao meio dia na porta da instituição e só chegou às $18 \mathrm{~h}$, horário em que já se está escuro em Recife. Da última vez que isso aconteceu, Elisa discutiu com o motorista na frente de Dora, chegou em casa aos prantos e o marido quis "tirar satisfação" com o rapaz. Após o conflito, Elisa ficou muito abatida, recordou que já havia deixado de frequentar um centro terapêutico porque um outro motorista achava o local muito distante das outras rotas hospitalares que fazia para a prefeitura daquele município. No entanto, essa mãe de micro o denunciou e a administração local afastou o motorista. Elisa e a filha passaram a circular em outro carro e com outro funcionário do município, mas ela ainda temia que pudesse enfrentar conflitos semelhantes novamente.

O mesmo ocorreu com Roberta, uma mulher negra, residente de outra cidade do interior. Nesse caso, o motorista partiu sem levar mãe e filha para a casa, porque saíram um pouco atrasadas da clínica de reabilitação (Alves \& Safatle 2018). Elas foram deixadas por 37 horas na 'rua', tendo que encontrar soluções improvisadas para pernoitar, medicar, alimentar a criança. Roberta denunciou a prefeitura e o motorista foi afastado (Alves 2018).

Algo semelhante aconteceu, em um ônibus que fazia linha de um bairro ao centro do Recife, com Margarida. Ela conta:

No começo teve vez que o motorista não quis levar ele, a gente bateu boca e tudo mais, daí eu anotei a placa do ônibus e reclamei... O ruim é que o motorista foi demitido e eu não queria isso, queria que ele levasse uma advertência para isso não acontecer mais, porque, no fim, ele também tem família e precisa botar comida dentro de casa, sabe? Mas agora que sei meus direitos, as coisas tão mudando (Diário de campo, 24/02/2018). 
O problema com o transporte é recorrente na realidade dessas mulheres. Muitas utilizam do transporte concedido pelas respectivas prefeituras (carros de passeio, ambulâncias ou vans, como é o caso do programa PE Conduz $z^{9}$ ); outras utilizam o passe livre e em algumas ocasiões conseguem organizar caronas ou dividem o valor de Uber ou do taxi entre um espaço e outro. No entanto, estes serviços têm falhado com essas mulheres. Seja pela má vontade do motorista de não colocar a cadeirinha do bebê no carro/van que a prefeitura disponibiliza, seja por oferecer apenas uma rota para estas mulheres mesmo sabendo que elas têm vários outros destinos necessários, seja pelo desrespeito de motoristas que atrasam ou se negam a transportar suas passageiras. Essa é uma face muito cruel do tratamento que essas crianças recebem na esfera pública, perante suas especificidades. É desrespeitar a mãe, na condição de cuidadora, e é desrespeitar a criança, na condição de sua deficiência e 'prioridade', que parece não funcionar plenamente nesses serviços. Acima de tudo, quando estas mulheres desanimam ou faltam às terapias ou a eventuais reuniões, são exclusivamente culpabilizadas, reforçando as desigualdades do gênero em todos esses papéis.

À medida que o tempo passa, as demandas das famílias em questão vão se modificando e intensificando, como no caso das narrativas acima, nas quais podemos observar o lugar central da busca e reinvindicação por um tratamento humanizado a seus filhos, tanto como pela reinvindicação de um transporte mais eficiente, por representar mais que um meio de locomoção, mas por ser o espaço em que elas passam boa parte de seu tempo.

Este é um dos maiores desafios no cotidiano de mães e filhos. As repercussões que o transporte traz são muitas: quando o motorista atrasa ou falta, elas perdem a terapia e podem ser 'cortadas' dos mesmos. Podem também ficar sem ter como voltar para casa; a comida e os remédios da filha acabarem e podem ainda fazer com caminhem sob o sol equatorial os longos percursos com filho, cadeira e bolsas, sozinhas e sobrecarregadas. O número de prejuízos que o transporte ocupa nessa rotina as desanima bastante. Contudo, elas reagem, recla- 
mam e expõem a situação, mas não é suficiente para reverter os traumas ou acostumar-se a eles, como Elisa evidenciou em nossa conversa: "Ninguém da família cuida como eu. Eu não me acostumo, a gente sofre com as crises, a gente sofre com a distância, com a rotina, com o transporte, e por atendimento e eu não quero me acostumar a isso" (Diário de campo, 20/09/2018).

Eis, portanto, uma descrição panorâmica de um dia típico dessas mulheres, saída de casa, traslado até a RMR, comparecimento às terapias, consultas e exames, traslado de volta à casa, assunção das tarefas domésticas e familiares. Elisa, Roberta, Margarida, por exemplo, têm essa rotina centrada em acordar cedo, frequentar centros terapêuticos e agendar as próximas consultas e terapias. Como a primeira interlocutora disse: "O tempo é o que me mata". Ela se refere ao tempo de deslocamento numa grande metrópole brasileira; tempo de agendamentos e esperas por consultas; tempo entre uma terapia ou outra; tempo de discutir com um funcionário; tempo de descobrir como reclamar, denunciar, processar um motorista, uma companhia de transporte, uma prefeitura; tempo de ir até o balcão de atendimentos, de providenciar os documentos exigidos, de voltar para cobrar o andamento de uma requisição etc. São muitos tempos sucessivos, simultâneos, intercortados.

\section{'O que adianta conhecer muita gente e no fim das contas estar sempre só?’}

Além dessa logística que é comum a todas as mães e familiares que partilham da experiência de ter um filho com deficiência, muitas destas mulheres agora participam de reuniões, palestras, rodas de empoderamento e cursos promovidos, na maioria das vezes, pelas redes de apoio mencionadas, a UMA e a AMAR. Outras atividades como reuniões com a secretaria do transporte ou seminários científicos também têm permeado a agenda de muitas delas. A maternidade, aqui, tem sido apresentada de uma forma intensificada, em que: 
"A partir da doença do filho caçula, elas tiveram que assumir mais uma carga de trabalho, enquanto se avolumavam as tarefas domésticas deixadas para trás. Muitas vezes, passavam os dois turnos diurnos na rua e retornavam exaustas ao final do dia para ainda lidar com comida, roupa, faxina, tarefas escolares e obrigações conjugais. Muitas contaram da sensação de exaustão física e também psicológica, já que precisavam aceitar, entender e aprender o que se passava com os filhos, ao mesmo tempo que responder aos questionamentos de maridos enciumados, atender à saudade dos outros filhos, responder às inquietações da família e da vizinhança perante a novidade apresentada pela deficiência” (Carneiro \& Fleischer 2017:23).

O que chama atenção nessa estrutura é a maneira como muitas dessas mulheres, como Elisa, têm reorientado seus projetos de vida em torno dessas crianças. A circulação por todos esses (novos) lugares reflete em como o tempo tem sido construído com base em uma reconfiguração destes cotidianos. O tempo é envolvido nas necessidades destas crianças para que não lhes falte transporte, comida, remédios, assistência e tecnologias de saúde.

A preocupação e dedicação em estar presente no circuito terapêutico e hospitalar do filho Marcelo, com três anos de idade, é uma constante na vida de Cecília, uma mãe de micro, branca, de 24 anos, e que tem outros dois filhos de quatro e seis anos. Moradora recente da cidade de Jaboatão dos Guararapes (também na RMR), dentro de casa ela se desdobra na atenção que tem que dar aos filhos mais velhos e na 'coterapia'. Essa é uma modalidade que tem sido divulgada, em que as mães de micro devem realizar, em casa, as terapias que foram aprendidas nas clínicas ou, às vezes, aprendidas de modo autodidata na internet. Vão assistindo a novos exercícios terapêuticos, descobrindo jeitos outros de trabalhar a tão preconizada estimulação precoce com a criança. Essas mulheres estão a desafiar o tempo, tentando oportunizá-lo na rua, em tantas clínicas e hospitais, mas também ampliando-o em casa, ao replicar e reinventar o que vêm aprendendo. Seria exatamente a ideia de 'dever de casa', prescrito e recomendado pelas clínicas, como Mattingly e seus colegas também notaram no cuidado com crianças com deficiências em sua etnografia na Califórnia (2011). 
Antes de sair de casa com o caçula na cadeira de rodas, Cecilia deixa os mais velhos na escola, perto de casa, mas passa o dia todo atenta com o horário no qual precisa buscá-los. A família não é uma rede presente, nem a vizinhança e, tão pouco, o pai das crianças. Cecilia explica, "Não dá para contar com família, não, só tenho eu, sou por mim e só tenho eu para Marcelo”. Certa vez, precisou abrir mão de comprar um armário em nome do parapodium ${ }^{10}$ do filho. De última hora, a irmã de Cecilia mudou de ideia e não arcou com essa despesa, que havia prometido fazer em nome do sobrinho. Entre muitas outras coisas, isso a deixou muito descrente com o 'apoio familiar', havia todo uma 'ginástica financeira' que ela precisa fazer para manter a casa e os três filhos (Fleischer 2017). Como costuma dizer, "Sou eu mesma para tudo".

Além das clínicas de reabilitação que frequenta, faz parte da AMAR. Embora seja mais um lugar para frequentar, exigindo a logística de circulação ao redor da cidade, essa instituição tem diminuído os altos orçamentos com as despesas de Marcelo, por meio de doações (fraldas, leite, cesta básica, medicamentos). Em uma de suas idas até a ONG, o motorista de uma van, que levava as mães até a clínica de reabilitação se recusou a levá-la, porque um de seus documentos não estava em dia ${ }^{11}$. Essa não foi a primeira vez que Cecilia e outras mães de micro tiveram entreveros com os encarregados pelas vans das prefeituras, os gestores das secretarias municipais, os motoristas e cobradores dos ônibus. $\mathrm{O}$ espaço do transporte é permeado por conflitos diários. A primeira autora não presenciou a cena, mas ouviu o relato posterior por parte de Cecilia:

Ela saiu caminhando até a parada de ônibus, com Marcelo na cadeira de rodas e uma cesta básica a tiracolo. As mães que ocupavam a van o mandaram parar o transporte para ela subir e o motorista, mesmo de cara fechada, teve que parar. Cecília contou que se sentiu desconfortável com a situação: 'Eu não volto com ele, não, primeiro, que ele não quer me levar e, segundo, porque eu já cansei de humilhação, eu me resolvo eu mesma'. (Diário de campo, Raquel Lustosa). 
Ainda na ocasião descrita anteriormente, ela questionou sobre a desatenção que tem sofrido, mesmo participando de redes de empoderamento: "O que adianta conhecer muita gente e no fim das contas estar só, sempre só”. A solidão de Cecília fazia menção ao abandono que tem vivenciado nos cuidados com o filho, bem como o maltrato sistemático que vem vivenciado no transporte. Mesmo com a ajuda da AMAR e das colegas com quem divide essa rede, era difícil que ela se sinta plenamente acolhida. É como se todo esse 'refazer' cotidiano do tempo e das tarefas não fosse suficiente para ser reconhecida como 'boa mãe'. Mais recentemente, Cecília estava grávida e compartilhava da solidão em uma outra dimensão, estava mais relacionada aos seus direitos reprodutivos e com poucas alternativas de cuidar dessa gestação, fazer o pré-natal, preparar enxoval, planejar os móveis e uso do espaço da casa etc. ${ }^{12}$ Além de tudo isso, uma nova maternidade soa como inapropriada diante da atenção que se 'deve dar' ao filho com a síndrome e, neste sentido, outras questões ressurgem à luz desse impasse: o controle e a vigilância reprodutiva da mulher.

\section{Consideração finais}

A discussão que envolve categorias como gênero, maternidade e cuidado se perpetua de forma histórica e vigorosa nas teorias feministas, como bem apontado pela socióloga Lucila Scavone (2004). Com esse pano de fundo e interessada em temas que envolvem a saúde reprodutiva da mulher, a autora nos mostra que os padrões circunscritos no modelo de maternidade têm mudado ${ }^{13}$, mas ainda são esmagadoramente associados 'às identidades femininas". Como afirma, "essa configuração da maternidade leva inevitavelmente ao questionamento da atuação exclusiva do sexo feminino na maior parte das funções atribuídas ao ser mãe" (Scavone 2004:156) e que implica o cuidado de forma coextensiva. Cecília, nossa última interlocutora, ao enfatizar que enfrenta, geralmente sozinha, todas as situações que demandam cuidado aos filhos, nos mostra uma realidade muito semelhante à de 
outras mulheres e mães de modo geral. A ênfase na primeira pessoa, "sou eu para tudo", é uma expressão que resume as inúmeras tarefas que mulheres como Cecília tem arcado.

Todo esse conjunto de responsabilidades envolvido nesse tipo específico de maternidade aparece atrelado ao dever moral de ser uma 'boa mãe', coexistindo ao dever do cuidado e do autocuidado, categorias mobilizadas pelos marcadores de gênero, classe e raça, e que nos sensibilizam a compreender a pluralidade de definições que essas maternidades assumem. Não são só 'deveres' que orientam essas relações. O antropólogo Diego Pinheiro (2019), por exemplo, aponta três caminhos em que as diversas maternidades do contexto SCZV podem ser compreendidas : a) na forma de 'dom' - da qual há um enorme compromisso (por parte da mãe) em cuidar do presente, que é o 'anjo' ${ }^{14}$ (filho), doado por uma divindade que lhe abençoou; b) ligando a perspectiva da maternidade ao cuidado, como uma forma de personificar o cuidado através de quem cuida, que não necessariamente é a mãe consanguínea, mas que recebe o nome de mãe numa relação implicada entre 'ser mulher' e 'ser mãe' (Banditer 2010), pois "mãe é quem cuida" e c) uma maternidade que se torna um potente discurso de legitimidade para quem tem "a experiência (expertise) de cuidar", o que em outras palavras significa que algumas personagens se diferenciam de outras por estarem inclinadas há um tempo maior na relação com o universo infantil, da deficiência e do cuidado de um modo geral. Todas essas três caracterizações feitas por Pinheiro servem para ajudar a entender o contexto de nossas interlocutoras no Recife. Recai sobre a mulher uma múltipla jornada de trabalho encarados como desafios e responsabilidades na maternidade no contexto de SCZV. Nessas condições é preciso estar a par de novas tecnologias, de novas técnicas terapêuticas, novos nomes, novos lugares e, em consequência, novas sociabilidades. O dever do cuidado aparece estritamente ligado ao gênero, assumida nesta maternidade. Tratase de um conjunto de atribuições designadas a estas, que em grande parte compõem a população negra - relegadas às más condições de 
saneamento básico, às precariedades do atendimento da saúde e do transporte público e à invisibilidade do valor de seu trabalho (que não se encaixa nas formalidades do trabalho remunerado).

Aqui existe um tempo narrado a partir de um fenômeno urgente, como nos mostra as histórias de nossas interlocutoras, nesses primeiros três anos desde a eclosão da epidemia. Os estudos do "uso no tempo" ampliam o debate sobre o tipo de trabalho que essas mulheres realizam, um trabalho que "envolve atividades contínuas e repetitivas, e requerem o engajamento afeito e a presença constante" (Bandeira, Preturban 2016:48). O tempo atravessa todas as experiências vividas por essas mulheres, ele é determinante na maternidade dentro e fora de casa. Se mostra como desafio impetuoso, como nos apontam as autoras Lourdes Bandeira e Renata Preturban:

"Trata-se de uma relação de serviço [e não só] que é exercida predominantemente por mulheres, portanto decorrente das relações sociais de gênero, e que demanda a disponibilidade permanente do uso do tempo feminino. Para realiza-los, as mulheres mobilizam-se não apenas em relação às suas habilidades físicas, mas também é necessário a mobilização de outras habilidades" (Bandeira \& Preturban 2016:48).

Uma vez que as redes amenizam algumas das angústias, o sofrimento e o medo que sentem em relação ao futuro incerto dessas crianças e as tornam agentes mediadoras entre as autoridades biomédicas, institucionais e não governamentais, elas também experienciam uma solidão compartilhada pela desigualdade de gênero, de raça e pela deficiência de seus filhos. Ainda que partilhem da experiência de acessar novos lugares sociais juntas, percorrem trajetos, na maioria das vezes, sem alguém que ajude a carregar o filho, literal e metaforicamente falando. Experimentam de uma cooperação atenciosa e ativista, como também vivenciam tantos tipos de solidão (Alves \& Safatle, no prelo), como a solidão da 'alta terapêutica' (Carneiro Fleischer 2017), a solidão da desinformação, a solidão da negação de seus filhos e a solidão do julgamento. 
O empoderamento por meio da linguagem técnica, do conhecimento biomédico e dos afetos ajudam a lhes sustentar a corda bamba das desigualdades que vivenciam cotidianamente. A especificidade do contexto presente abre caminhos para pensarmos em um tipo de maternidade que ultrapassa a ideia da maternidade 'mandato' ou 'amparada', como explica Carneiro ao apresentar as 'fases' da maternidade em uma leitura feminista (Carneiro 2015:20). A maternidade pode ser lida como uma maternidade militante ou também uma maternidade 'missão' (Longhi \& Pinheiro 2017), em que o cuidado, tão central em todas as esferas deste cenário, "não coincide com alienação e autoanulação" (Carneiro 2015:35). É possível captar "outros registros da maternidade", como propõe essa autora. No entanto, devemos apontar de que forma essa maternidade recai, por muitas vezes com desânimo e cansaço, em suas rotinas, justamente por essa 'intensificação' da qual tratamos aqui: seja no transporte, na fila da farmácia do Estado, no enfrentamento do preconceito com outra forma corporal ou seja no lugar de culpabilização por eventualmente desanimar ou precisar, por tantos motivos, faltar às terapias, deixar de participar da ONG, não mais receber pesquisadores em sua casa. Reconheciam que a SCVZ havia lhes apresentado a 'muita gente', mas nem sempre havia o apoio suficiente ou adequado para as necessidades intensas que seus filhos the demandavam. A todo tempo, maternidade, cuidado e solidão apareciam em arranjos diferentes.

\section{Notas}

1 A OMS decretou, em fevereiro de 2016, como estado de emergência internacional a epidemia do Zika vírus. Em novembro do mesmo ano, a organização pôs fim a esse decreto, alegando não ser mais o caso, negligenciando assim todo uma rede de pessoas afetadas pelo epifenômeno a longo prazo.

2 Ver boletim epidemiológico, disponível em: http://portalarquivos2.saude.gov. br/images/pdf/2018/janeiro/30/2018-002.pdf.

3 Em parte, a falta de recursos à essas crianças se dá pelo baixo número de casos de SCZV nessas duas regiões (Bezerra 2019). 
4 Em amplitudes maiores as respostas cobradas são relativas ao número de pesquisas que são realizadas com essas famílias. Em uma entrevista realizada recentemente com uma das lideranças desta $\mathrm{ONG}$, a recorrente não devolução dos resultados das pesquisas foi muito criticada. De acordo com esta liderança, "não ter resposta (às emergências do zika) é uma resposta”. E, mesmo que os pesquisadores ainda não possam oferecer conclusões definitivas, faz parte do compromisso ético de toda e qualquer pesquisa assumir isso.

5 Geralmente, falava-se que o bebê 'nasceria morto', ou 'vegetaria', ou 'veria só vulto' caso conseguisse enxergar.

6 As lideranças locais, especificadamente as ONGs UMA e AMAR, têm divulgado que mais de $70 \%$ das crianças com SCZV foram abandonadas pelo pai.

7 Por incrível que pareça, faltam pesquisas que aprofundem a categoria 'raça' na área da saúde (Laguardia 2004).

8 Mas a forma com que tem sido oferecida pode ser bastante problemática e controversa (Fleischer \& Carneiro 2017).

9 "Coordenado pela Superintendência Estadual de Apoio à Pessoa com Deficiência, o Programa PE Conduz, é um serviço gratuito do Governo do Estado, conforme Lei no. $15.106 / 2013$. O programa atua de segunda a sexta-feira no Grande Recife; nos polos do Agreste Central, nas Zonas da Mata Norte e Sul e no Sertão do São Francisco, atendendo em vans adaptadas, pessoas com deficiência com severa dificuldade de mobilidade" (http://www.portais.pe.gov.br/web/sedsdh/pe-conduz).

10 O parapodium é um objeto utilizado para fisioterapia e serve para ajudar a criança a corrigir sua postura, melhorar seu equilíbrio em pé.

11 Para utilizar este transporte é necessário que o cadastro esteja atualizado e geralmente os motoristas tem uma lista com o nome dos usuários atualizados.

12 Por último, um desafio novo tem se mostrado bastante revelador para pensar o trato com a maternidade neste contexto: a gravidez e a chegada de um novo bebê nessas famílias, mas nos aprofundaremos nesse tema em outra oportunidade.

13 De acordo com a autora esse modelo de maternidade deslocada da seara biologizante (determinante) tende a ter outras conotações se tomadas a partir da mudança das/nas tecnologias reprodutivas; dos métodos contraceptivos; do controle da taxa de natalidade; nas transformações dos arranjos familiares e questões a eles subjacentes. Em geral, essas mudanças se diferenciam nas relações sociais, porque variam de uma classe social à outra (Scavone 2004).

14 A principal referência da UMA são os anjos enviados como presentes e compromisso de luta.

\section{Referências}

ALVES, Raquel L. C. 2018. "Um dia com Josi: uma fotoetnografia do cuidado e do cansaço". Interface, 22(66):975-980. (www.scielo.br/scielo.php?script=sci_abstract\&pi$\mathrm{d}=\$$ S1414-32832018000300975\&lng=en\& $\mathrm{nrm}=$ iso\& $\mathrm{t}$ lng=pt; acesso em 20/10/2018). 
ALVES, RaquelL.C. "Mãe e bebê com microcefalia são abandonados por 37 horas nas ruas de Recife, 2018”. Brasil de Fato. (www.brasildefato.com.br/2018/05/16/ relato-or-mae-e-bebe-com-microcefalia-sao-abandonadas-por-37-horas-nas-ruasde-recife/>; acesso em 28/10/2018).

ALVES, Raquel \& SAFATLE, Yasmin. 2019. "Mães de micro: uma etnografia do cuidado e do cansaço". Revista Áltera, no prelo.

BANDEIRA, Lourdes \& PRETURBAN, Renata. 2016. "As pesquisas sobre uso do tempo e a promoção de igualdade de gênero no Brasil”. In FONTOURA, N. et al. (eds.): Uso do tempo e gênero, pp. 49-61. Rio de Janeiro: UERJ.

BEZERRA, Amarílis Bahia. 2019. Série de Casos: Caracterização da mobilidade e do acesso de crianças com Sindrome Congênita por Zika e Storch aos serviços de estimulação precoce no Distrito Federal. Dissertação de Mestrado. Brasília: Universidade de Brasília.

BRITO, Débora de. 2016. "Um ano de Zika: As mulheres no centro da epidemia”. (http://agenciabrasil.ebc.com.br/especial/2016-11/um-ano-de-zika-mulheresno-centro-da-epidemia; acesso em 28/10/2018).

CRENSHAW, Kimberle. 1993. "Mapping the margins: intersectionality, identity politics, and violence against women of color". Stanford Law Review, 43:12411299.

CARVALHO, Layla. 2017. "Vírus Zika e direitos reprodutivos: entre as políticas transacionais, as nacionais e as ações locais". Caderno de Gênero e Diversidade, 3(2):93-102. (https://portalseer.ufba.br/index.php/cadgendiv/article/ view/22030; acesso em 29/10/2018).

CARNEIRO, Rosamaria Giatti. 2015. Cenas de Parto e Politicas do Corpo. Rio de Janeiro: Editora Fiocruz.

CARNEIRO, R. \& FLEISCHER, S. 2018. “'Eu não esperava por isso. Foi um susto': conceber, gestar e parir em tempos de Zika à luz das mulheres de Recife, PE, Brasil”. Interface, 22(66):709-719.

. s/d. "Em Brasília, mas em Recife: atravessamentos tecno-metodológicos em saúde, gênero e maternidades numa pesquisa sobre as repercussões da epidemia do vírus Zika”. No prelo.

DINIZ, Debora. 2007. O que é Deficiência? São Paulo: Brasiliense.

2016. Zika: do Sertão nordestino à ameaça global. Rio de Janeiro: Civilização Brasileira.

HIRATA, Helena. "O trabalho do cuidado". Sur - Revista Internacional de Direitos Humanos, 13(24):53-64.

FARIAS, J. \& VIANNA, A. 2011. "A guerra das mães: dor e política em situações de violência institucional”. Cadernos Pagu, 37:79-116.

FLEISCHER, Soraya. 2017. "Segurar, caminhar e falar: notas etnográficas sobre a experiência de uma "mãe de micro" no Recife/PE". Caderno de Gênero e Diversidade, 3(2):93-112.

2018. "Cenas de microcefalia, de cuidado, de antropologia" (Recife, setembro de 2017). Cadernos de campo, no prelo. 
FLEISCHER, S. \& CARNEIRO, R. 2017 . "A alta terapêutica de crianças com a síndrome congênita do vírus Zika: $\mathrm{O}$ que esse fenômeno pode nos contar sobre o estado atual da epidemia?”. In BRAZ, C. \& HENNING, C. (eds.): Gênero, sexualidade e saúde: diálogos latino-americanos, pp. 17-51. Goiânia: Editora da Imprensa Universitária.

HAN, Clara. 2012. Life in debt: times of care and violence in neoliberal Chile. Los Angeles: University of California Press,

GONÇALVES, Ana Maria. 2006. Um defeito de cor. Rio de Janeiro: Record.

LIRA, C. L et al. 2017. "Trocas, Gênero, Assimetrias e Alinhamentos: experiência etnográfica com mães e crianças com a síndrome congênita do Zika”. Revista Anthropológicas, 28(2):206-237.

MAISONNAVE, Fabiano. "Oito em cada dez bebês com danos do zika nascem de mães negras". Folha de São Paulo, publicado em 12/09/2016. (www1.folha.uol. com.br/cotidiano/2016/09/1812302-oito-em-cada-dez-bebes-com-danos-dozica-nascem-de-maes-negras.shtml>; acesso em 05/10/2017).

MALUF, S. \& TORNQUIST, C. (eds.). 2011. Gênero, saúde e aflição: abordagens antropológicas. Florianópolis: Letras Contemporâneas.

MATTINGLY, C., GRØN, L. \& MEINERT, L. 2010. "Chronic homework in emerging borderlands of healthcare”. Culture, Medicine and Psychiatry, 35:347-375.

PACHECO, Ana Cláudia. 2013. Mulher negra: afetividade e solidão. Salvador: Editora da Universidade Federal de Bahia.

PINHEIRO, D. \& LONGHI, M. 2017. "Maternidade como missão! A trajetória militante de uma mãe de bebe com microcefalia em PE". Revista Cadernos de Gênero e Diversidade, 3(2):113-133.

PINHEIRO, Diego. 2019. “'Mãe é quem cuida': A Legitimidade da maternidade no discurso de mães de bebês com microcefalia em Pernambuco”. MediaçõesRevista de Ciências Sociais, 23(3):132-163.

RIBEIRO, Djamila. 2018. Quem tem medo do feminismo negro? São Paulo: Companhia das Letras.

SCAVONE, Lucila. 2004. Dar a vida e cuidar da vida. Feminismo e Ciências Sociais. São Paulo: Editora Unesp.

SCOTT, R. P. et al. 2017. "A epidemia de zika e as articulações das mães num campo tensionado entre feminismo, deficiência e cuidados”. Caderno de Gênero e Diversidade, 3(2):93-102.

SILVA, R. A. et al. "Economia Política do Zika: 2017. Realçando relações entre Estado e cidadão”. Revista Anthropológicas, 28(1):223-246.

VENÂNCIO, Lays. 2017. Mães de Micro: Três redes de cuidado e apoio no contexto do surto da síndrome congênita do vírus zika no Recife/PE. Trabalho de Conclusão de Curso. Brasília: UNB.

VALIM, Thais. 2017. 'Ele sente tudo o que a gente sente': Um estudo antropológico sobre a sociabilidade dos bebês nascidos com a síndrome congênita do Zika no Recife/PE. Trabalho de Conclusão de Curso. Brasília: UNB. 
Abstract: Three years after the outbreak of Zika Virus in Brazil, different impacts on the Brazilian population can be evidenced, especially in the lives of women who had children under these circumstances. Pernambuco, where the field research has been carried out, was the state with the most cases of births of babies with the Zika Virus Congenital Syndrome. Meanwhile, there is a scenario of many challenges from the public institutions, health professionals, children affected and, mainly, by their caregivers. The existence of support networks for these families, made up mostly of women facing a situation of social vulnerability prior to the epidemic, contributes to both the economic and the affective spheres of 'micro mothers' - as they decided to name themselves. But even so, the burden of tasks directed at these women, be it mother, sister, grandmother or aunt, is insurmountable. She is responsible for the daily care of this baby, she is the one who faces difficult routes in the therapeutic itineraries, and it is she who, together with her daughter or her son, experiences discrimination from a society so unprepared to deal with the specificities of a disabled person. From the ethnography carried out with the 'micro mothers' from the city of Recife, the present work seeks to reflect the ambiguity relations produced in this scenario; on the one hand there is subject empowering with the relationships built through support networks, on the other hand, there is tiresome and loneliness. In this sense, the anthropological gaze helps us understand how these women have reassigned motherhood and, above all, how loneliness has been reflected upon, intending the intersectionality of gender, class, race and disability.

Keywords: Maternity, Zika Virus, Loneliness, Medical Anthropology.

Recebido em outubro de 2018. Aprovado em dezembro de 2018. 